\title{
СТРУКТУРА АСФАЛЬТЕНОВ НЕФТЕЙ РАЗЛИЧНОЙ ХИМИЧЕСКОЙ ПРИРОДЫ
}

\author{
Чешкова Татьяна Викторовна', \\ chtv12@mail.ru
}

\author{
Сергун Валерий Петрович', \\ sergun@ipc.tsc.ru
}

\section{Коваленко Елена Юрьевна', azot@ipc.tsc.ru}

\section{Сагаченко Татьяна Анатольевна', dissovet@ipc.tsc.ru}

\author{
Мин Раиса Сергеевна', \\ Igosn@ipc.tsc.ru \\ 1 Институт химии нефти Сибирского отделения Российской академии наук, \\ Россия, 634055, г. Томск, пр. Академический, 4.
}

\begin{abstract}
Актуальность работы обусловлена необходимостью получения и обобщения информации о составе и строении асфальтеновых компонентов нефтей различной химической природы, так как особенности структурных характеристик асфальтенов оказывают существенное влияние на глубину их термодеструкции. Особое значение работы в этом направлении получили в последнее время из-за неуклонного роста в составе разведанных и извлекаемых запасов тяжелых нефтей, которые отличаются от традиционных нефтей высоким содержанием асфальтенов.

Цель работы: сравнительный анализ структурно-группового состава асфальтенов типичной метано-нафтеновой нефти и тяжелой нефти нафтено-ароматического основания, молекулярного состава структурных фрагментов, связанных в молекулах их асфальтеновых компонентов через сульфидные и эфирные мостики, и ковалентно несвязанных соединений.

Методы исследования: элементный анализ, криоскопия в бензоле, экстракция, жидкостно-адсорбционная хроматография, селективная химическая деструкция сульфидных и эфирных связей, ЯМР'Н-спектроскопия, структурно-групповой анализ, хроматомасс-спектрометрия.

Результаты. Проведен сравнительный анализ состава и структуры асфальтеновых компонентов нефтей метано-нафтенового и нафтено-ароматического типов. Выявлены сходства и различия в их структурно-групповом составе, составе фрагментов, связанных в молекулах асфальтенов через эфирные и сульфидные мостики, и составе соединений, окклюдированных макромолекулами асфальтеновых веществ. С использованием методов мягкой химической деструкции сульфидных и эфирных связей показано, что наиболее распространенными фрагментами макромолекул асфальтенов нефтей метано-нафтенового и нафтено-ароматического типов являются н-алканы, циклогексаны, стераны, гопаны, н-алкилбензолы и н-алкилтолуолы. Особенностью молекул асфальтенов метано-нафтеновой нефти является присутствие в составе их структурных фрагментов алкенов, непредельных стеранов, а нафтено-ароматической нефти - прегнанов, хейлантанов, тиофеновых соединений и этиловых эфиров алкановых кислот.
\end{abstract}

\section{Ключевые слова:}

Нефть, асфальтены, структурно-групповой состав, селективная химическая деструкция серо- и эфиросвязанные фрагменты, состав, насыщенные и ароматические углеводороды, гетероорганические соединения.

\section{Введение}

Информация о строении асфальтенов нефтяных дисперсных систем (НДС) играет значительную роль при решении ряда фундаментальных и прикладных задач, связанных с генезисом нефтей, их добычей, транспортировкой и переработкой [1-6]. Несмотря на большой объем работ по асфальтеновым веществам, химическая природа этих компонентов изучена недостаточно, что во многом обусловлено чрезвычайной сложностью строения асфальтенов, представляющих собой непрерывный ряд соединений с различной молекулярной массой, полярностью и растворимостью [7-13]. В отличие от остальных компонентов нефти, асфальтены более склонны к образованию молекулярных ассоциатов в виде коллоидных частиц значительных размеров. В составе таких частиц собственно асфальтеновые молекулы образуют ядра, на поверхности которых адсорбируются молекулы гетероатомных и углеводородных компонентов нефтяных дистиллятов $[14,15]$. Формирование асфальтеновых агрегатов различных иерархических уровней неразрывно связано с составом и строением асфальтеновых молекул, а соотношение этих уровней оказывает влияние на физико-химические свойства НДС [16-21]. В связи с этим накопление информации об особенностях состава, структуры и свойств афальтеновых веществ нефтей различных химических типов является важной и актуальной задачей. Особое значение работы в этом направлении получили в последнее время из-за неуклонного роста в составе разведанных и 
извлекаемых запасов тяжелых нефтей, которые отличаются от традиционных нефтей высоким содержанием асфальтенов.

В рамках данного сообщения обобщены полученные авторами экспериментальные данные о составе и структуре асфальтеновых компонентов типичной нефти метано-нафтенового основания [22] и тяжелой нефти нафтено-ароматического типа [23-25].

\section{Экспериментальная часть}

Объекты исследования - асфальтены нефтей промышленно разрабатываемых месторождений Крапивинское (Западная Сибирь, терригенные отложения, верхнеюрская залежь [26]) и Усинское (Республика Коми, карбонатные отложения, пермо-карбоновая залежь [27]) (табл. 1).

Таблица 1. Характеристика объектов исследования

Table 1. Properties of the objects under study

\begin{tabular}{|c|c|c|c|c|c|c|}
\hline \multirow{2}{*}{ 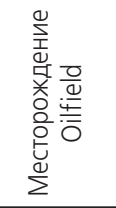 } & \multirow{2}{*}{ 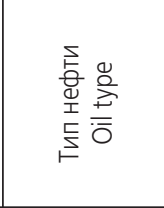 } & \multirow{2}{*}{ 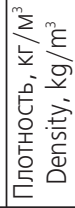 } & \multicolumn{4}{|c|}{$\begin{array}{c}\text { Содержание, \% мас. } \\
\text { Content, wt. \% }\end{array}$} \\
\hline & & & $\mathrm{N}$ & $S$ & $\begin{array}{c}\text { Асфальтены } \\
\text { Asphaltens }\end{array}$ & $\begin{array}{l}\text { Смолы } \\
\text { Resins }\end{array}$ \\
\hline $\begin{array}{c}\text { Крапи- } \\
\text { винское } \\
\text { Krapivinsk }\end{array}$ & $\begin{array}{c}\text { метано- } \\
\text { нафтеновая } \\
\text { methane- } \\
\text { naphthenic }\end{array}$ & 867 & 0,35 & 1,05 & 2,6 & 8,8 \\
\hline $\begin{array}{c}\text { Усинское } \\
\text { Usinsk }\end{array}$ & $\begin{array}{c}\text { нафтено-аро- } \\
\text { матическая } \\
\text { naphthene- } \\
\text { aromatic }\end{array}$ & 1008 & 0,62 & 2,04 & 11,2 & 19,1 \\
\hline
\end{tabular}

Подготовка образцов к анализу включала стадии разделения асфальтенов на высоко- (BMA) и низкомолекулярные (HМА) компоненты и соединения, адсорбированные/окклюдированные их молекулами - «мальтены» $[21,28]$, и хроматографического разделения "мальтенов» на фракции относительно малополярных (фракция А) и полярных соединений (фракция В), элюируемых смесями гексана с бензолом (1:1 по объему) и метанола с хлороформом (1:4 по объему).

Для характеристики полученных продуктов использовали комплекс физико-химических методов: определение элементного состава (C, H, N, S на анализаторе «Vario EL Cube», $\mathrm{O}$ - по разности между $100 \%$ и содержанием элементов C, $\mathrm{H}, \mathrm{N}$, S), измерение средних молекулярных масс (MM) методом криоскопии в бензоле, селективную химическую деструкцию [22, 25, 28], ЯМР-Фурье спектроскопию, структурно-групповой анализ (СГА) [29], хроматомасс-спектрометрию (ГХ-МС).

Спектры ЯМР ${ }^{1} \mathrm{H}$ записывали на ЯМР-Фурье спектрометре «AVANCE AV 300» фирмы «Bruker» при 300 МГц в растворах $\mathrm{CDCl}_{3}$. В качестве стандарта использовали тетраметилсилан. По спектрам ЯМР ${ }^{1} \mathrm{H}$ проводили расчет относительного содержания протонов в различных структурных фрагментах, исходя из площадей сигналов в соот- ветствующих областях спектра: $H_{\text {ar }}$ (доля протонов, содержащихся в ароматических структурах) - 6,6-8,5 м.д.; $H_{\alpha}$ (доля протонов у атомов углерода в $\alpha$-положении к ароматическим ядрам) - 2,2-4,0 м.д.; $H_{\beta}$ и $H_{\gamma}$ (доля протонов в метиленовых и в концевых метильных группах алифатических фрагментов молекул, соответственно) $1,1-2,1$ и $0,3-1,1$ м.д. [30].

Метод СГА использовали для описания молекулярной структуры ВМА. На основе данных о МM, элементном составе и распределении протонов между различными фрагментами их молекул рассчитывали средние структурные характеристики молекул исследуемых веществ [29]. В ходе расчетов определены следующие параметры: $\mathrm{C}_{a}, \mathrm{C}_{\mathrm{H}}, \mathrm{C}_{\text {п }}-$ число углеродных атомов в ароматических, нафтеновых и парафиновых структурах средней молекулы соответственно; $\mathrm{m}_{\mathrm{a}}$ - число структурных единиц в средней молекуле; $\mathrm{K}_{0}^{*}, \mathrm{~K}_{\mathrm{a}}^{*}, \mathrm{~K}_{\mathrm{H}}^{*}$ - общее число, число ароматических и нафтеновых циклов в структурной единице; $\mathrm{C}_{\text {I }}^{*}$ - число атомов углерода в парафиновых фрагментах структурной единицы, $\mathrm{C}_{\alpha}^{*}$ и $\mathrm{C}_{\gamma}^{*}-$ количество атомов $\mathrm{C}$, находящихся в $\alpha$-положении к ароматическим ядрам и в не связанных с ароматическими ядрами терминальных метильных группах.

Разрыв әфирных и сульфидных связей в молекулах асфальтенов осуществляли с помощью трибромида бора и борида никеля, соответственно. Условия проведения селективных реакций описаны в [22, 25].

ГХ-МС анализ жидких продуктов хемолиза и малополярной фракции А «мальтенов» проводили на приборе DFS фирмы «Thermo Scientific». Условия получения спектров, их обработки и подходы к идентификации соединений приведены в работе [24].

Анализ образцов осуществляли с привлечением оборудования центра коллективного пользования Томского научного центра СО РАН.

\section{Результаты и их обсуждение}

Анализ результатов фракционирования исследуемых асфальтенов показал, что, независимо от типа нефти, они имеют сходный характер распределения соединений по ММ. Основной вклад в состав асфальтеновых компонентов вносят BMA (MM 1009 и 1500 а.е.м. для нефтей метано-нафтенового и нафтено-ароматического типов). Доля HMA (MM 550 и 770 а.е.м.) и «мальтенов» (MM 500 и 700 а.е.м.) значительно ниже. Нафтено-ароматическая нефть отличается от метано-нафтеновой нефти повышенным содержанием ВMA (92,2 против 87,1 \% отн.). Особенностью метанонафтеновой нефти является более высокое содержание HМА (5,4 против 3,7 \% отн.) и почти в два раза большее содержание «мальтенов» $(6,7$ против 3,4 \% отн.). Наиболее отличающиеся по выходу фракции асфальтенов (ВМА, «мальтены») были использованы для сравнительной характеристики асфальтеновых компонентов нефтей различной природы. 
Сравнительная характеристика высокомолекулярных асфальтенов

Анализ результатов СГА (табл. 2) позволил оценить величину и строение молекул основной массы асфальтеновых веществ метано-нафтеновой и нафтено-ароматической нефтей и выявить сходства и различия в их структуре.

Установлено, что средние молекулы ВМА тяжелой нафтено-ароматической нефти отличаются от средних молекул ВМА типичной нефти метанонафтенового типа большими значениями MM (1500 против 1009 а.е.м.), большим количеством углеродных атомов в ароматических $\left(\mathrm{C}_{\mathrm{a}} 43,94\right.$ против 23,23) и нафтеновых $\left(\mathrm{C}_{\text {н }} 49,97\right.$ против 43,31$)$ фрагментах и большим числом структурных единиц $\left(\mathrm{m}_{\mathrm{a}} 3,21\right.$ против 2,04). Однако в средних молекулах BMA метано-нафтеновой нефти структурные единицы крупнее (C*35,22 против 30,72), что обусловлено большим развитием нафтеновых $\left(\mathrm{K}_{\mathrm{H}}^{*} 8,67\right.$ против 3,98$)$ и алифатических фрагментов $\left(\mathrm{C}_{\text {I }}^{*} 2,60\right.$ против 1,48$)$.

В то же время молекулы ВМА обоих типов нефтей и присутствующие в них структурные единицы мало различаются по характеру лежащих в их основе полициклических систем и природе алифатических фрагментов. Так, близкое к четырем значение параметра $\mathrm{C}_{\alpha}^{*}(3,47$ и 4,70$)$ может свидетельствовать о размещении ароматических ядер на периферии нафтеноареновых структур, а равенство расчетных значений параметров $\mathrm{C}_{\mathrm{II}}^{*}$ и $\mathrm{C}_{\gamma}^{*}$ - о том, что алкильные заместители в структурных единицах средних молекул обоих образцов представлены только метильными группами.

Из сравнения данных о содержании гетероатомов следует, что в средних молекулах ВМА метано-нафтеновой нефти $30 \%$ структурных единиц содержат атом азота, 35 \% структурных единиц атом серы, а атом кислорода входит в структуру каждой структурной единицы. В случае нафтеноароматической нефти атом азота содержат $38 \%$ структурных единиц, атом серы - 50 \% структурных единиц, и каждая структурная единица содержит от 2 до 3 атомов кислорода.

Повышенная концентрация в образцах BMA серы и высокое содержание кислорода определили направление исследования структуры их молекул. Известно, что в молекулярной структуре асфальтенов важную роль играет сера в сульфидных связях, на долю которых может приходиться до 40 \% общей серы асфальтеновых веществ, и кислород в эфирных и сложноэфирных связях [28]. Функциональные группы простых и/или сложных эфиров и алифатических сульфидов могут выступать в качестве мостиков, осуществляющих в молекулах асфальтенов связь отдельных структурных фрагментов между собой или с поликонденсированным ядром их молекул [28]. Наличие такой мостиковой связи установлено в молекулах асфальтенов Атабаски [28], асфальтенов и смол тяжелой нефти Усинского месторождения [25, 31] и смолисто-асфальтеновых и ма- сляных компонентов ашальчинского битума [32, 33]. В связи с этим в работе уделено внимание сравнительной характеристике состава структурных фрагментов, связанных в молекулах исследуемых BMA через эфирные и сульфидные мостики.

Таблица 2. Расчетные значения структурных параметров молекул ВМА метано-нафтеновой (1) и нафтеноароматической (2) нефтей

Table 2. Calculated values of the structural parameters for (HMA) molecules in methane-naphthenic (1) and naphthenic-aromatic (2) oils

\begin{tabular}{|c|c|c|c|}
\hline \multicolumn{2}{|l|}{ Параметры/Index } & 1 & 2 \\
\hline \multicolumn{2}{|l|}{$\begin{array}{l}\text { Средняя молекулярная масса } \\
\text { Average molecular mass }\end{array}$} & 1009 & 1500 \\
\hline \multirow{5}{*}{$\begin{array}{l}\text { Элементный состав, мас. \% } \\
\text { Elemental composition, wt. \% }\end{array}$} & C & 85,44 & 78,92 \\
\hline & $\mathrm{H}$ & 7,47 & 6,86 \\
\hline & $\mathrm{N}$ & 0,89 & 1,14 \\
\hline & $\mathrm{S}$ & 2,34 & 3,42 \\
\hline & 0 & 3,86 & 9,66 \\
\hline \multirow{10}{*}{$\begin{array}{l}\text { Число атомов в средней молекуле } \\
\text { Amount of atoms in an average molecule }\end{array}$} & C & 71,84 & 96,65 \\
\hline & $\mathrm{H}$ & 74,77 & 102.08 \\
\hline & $\mathrm{N}$ & 0,64 & 1,22 \\
\hline & $\mathrm{S}$ & 0,74 & 1,60 \\
\hline & 0 & 2,43 & 9,06 \\
\hline & $\mathrm{C}_{\mathrm{a}}$ & 23,23 & 43,94 \\
\hline & $C_{H}$ & 43,31 & 49,97 \\
\hline & $\mathrm{C}_{\Pi}$ & 5,30 & 4,74 \\
\hline & $\mathrm{C}_{\alpha}$ & 7,08 & 15,10 \\
\hline & $C_{\gamma}$ & 5,30 & 4,74 \\
\hline $\begin{array}{l}\text { Число структурных единиц } \\
\text { в средней молекуле } \\
\text { Number of structural units in the average } \\
\text { molecule }\end{array}$ & $m_{a}$ & 2,04 & 3,21 \\
\hline \multirow{7}{*}{$\begin{array}{l}\text { Параметры средних структурных единиц } \\
\text { Parameters of average structural unit }\end{array}$} & $\mathrm{K}_{0}^{*}$ & 11,37 & 7,45 \\
\hline & $\mathrm{K}_{\mathrm{a}}^{*}$ & 2,69 & 3,47 \\
\hline & $\mathrm{K}_{\mathrm{H}}^{*}$ & 8,67 & 3,98 \\
\hline & $C^{*}$ & 35,22 & 30,72 \\
\hline & $\mathrm{C}_{\pi}^{*}$ & 2,60 & 1,48 \\
\hline & $\mathrm{C}_{\alpha}^{*}$ & 3,47 & 4,70 \\
\hline & $C_{\gamma}^{*}$ & 2,60 & 1,48 \\
\hline
\end{tabular}

* - относится к структурной единице

* - refers to a structural unit

Химическая деструкция алифатических связей C-S и C-O

Выход растворимых в гексане продуктов десульфуризации составляет 24,1 и 33,3 \% для молекул BMA метано-нафтеновой и нафтено-ароматической нефтей соответственно, что существенно выше, чем выход растворимых продуктов деструкции эфирных связей $(12,8$ и 9,6\%). Это может свидетельствовать о том, что в структуре ВМА исследуемых нефтей доля "серосвязанных" фрагментов выше доли фрагментов, содержащих эфирные связи. В то же время в структуре ВМА тяжелой нафтено-ароматической нефти выше доля фрагментов, связанных через сульфидные мостики, а в структуре BMА типичной метано-нафтеновой нефти - через эфирные. 

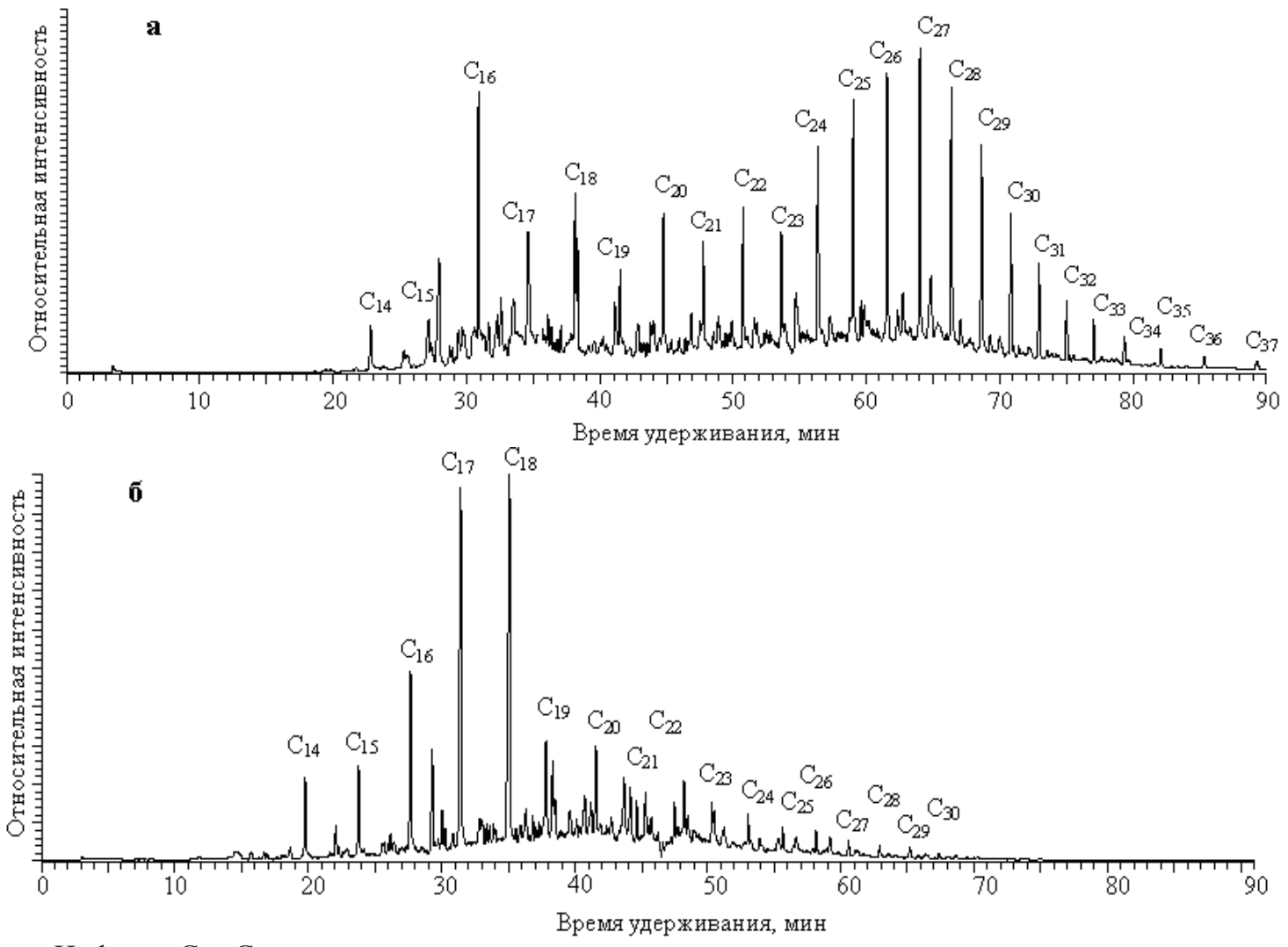

Цифры у $\mathrm{C}_{14}-\mathrm{C}_{37}-$ количество атомов углерода

Index number $\mathrm{C}_{14}-\mathrm{C}_{37}$ is the number of carbon atoms

Рис. 1. Масс-хроматограмма продуктов деструкции эфирных связей в молекулах ВМА метано-нафтеновой (а) и нафтено-ароматической (б) нефтей по иону с m/z 71 (н-алканы)

Fig. 1. Mass-chromatogram for the products of ether bonds destruction in the HMA molecules of methane-naphthenic (a) and naphthenic-aromatic (b) oils at the ion with $\mathrm{m} / \mathrm{z} 71$ (n-alkanes)

По данным ГХ-МС анализа в растворимых продуктах химической деструкции сульфидных и эфирных связей в молекулах ВМА нефтей обоих типов присутствуют алканы, нафтены, ароматические углеводороды (АУ) и гетероорганические соединения (ГОС) [22, 25]. При этом одни и те же представители «серосвязанных» и «эфиросвязанных" нафтенов и ароматических УВ в структуре молекул ВМА обеих нефтей имеют сходное распределение. Различия наблюдаются в молекулярном составе «связанных" н-алканов. В случае метанонафтеновой нефти эти насыщенные фрагменты молекул ВМА характеризуются большим числом атомов углерода в цепи и положением максимума молекулярно-массового распределения: $\mathrm{C}_{27}$ вместо $\mathrm{C}_{18}$ (рис. 1).

Особенностью молекул ВМА метано-нафтеновой нефти является также присутствие в составе их «серосвязанных» фрагментов алкенов и непредельных стеранов и более широкого спектра полициклических АУ [22]. Среди последних, кроме би- и трициклических соединений, установлены тетра-, пента- и гексациклические структуры (рис. 2).

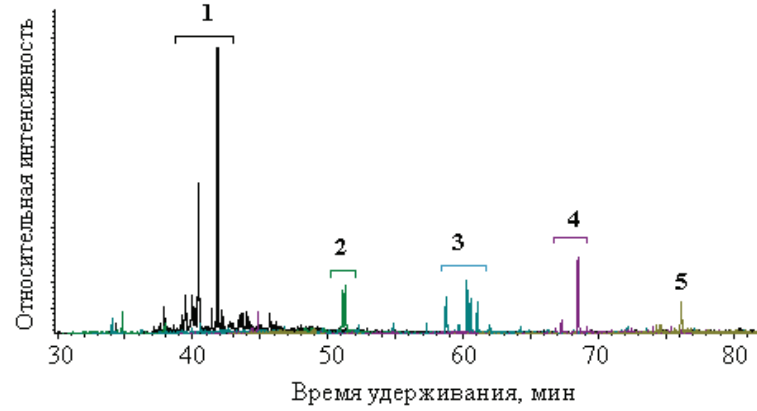

1-2, 3, 4-5 - тетра-, пента- и гексациклические ароматические углеводороды, соответственно 1-2, 3, 4-5 - tetra-, penta- and hexacyclic aromatic hydrocarbons, respectively

Рис. 2. Масс-хроматограмма продуктов деструкции сульфидных связей в молекулах ВМА метано-нафтеновой нефти по ионам c m/z 202 (1), 228 (2), 252 (3), 276 (4) и 302 (5)

Fig. 2. Mass-chromatogram for the products of sulfide bonds destruction in the HMA molecules of methane-naphthenic oil at ions with $\mathrm{m} / \mathrm{z} 202$ (1), 228 (2), 252 (3), 276 (4) and 302 (5) 
Наблюдаются различия и в составе продуктов деструкции эфирных связей. Так, только среди «эфиросвязанных» фрагментов молекул ВМА тяжелой нафтено-ароматической нефти идентифицированы три- и тетрациклические терпаны и гомологические ряды алкилзамещенных тиофенов и этиловых эфиров алифатических кислот [25]. Присутствие алкилтиофенов в структуре асфальтенов установлено авторами [34] в продуктах термической деструкции асфальтеновых компонентов Атабаски. Что касается идентифицированных этиловых эфиров, то они, вероятнее всего, окклюдированы BMA, так как хемолиз может приводить не только к разрушению ковалентных связей, но и к высвобождению соединений, находящихся внутри асфальтеновых структур [35].

Наличие идентифицированных в структуре BMA нефтей обоих типов нормальных алканов, циклогексанов, прегнанов и стеранов, хейлантанов и гопанов отмечено также в составе связанных фрагментов в молекулах ВМА асфальтенов Атабаски и нефтей Китая [28] и жидких продуктов термической деструкции асфальтеновых компонентов ивановского [36] и спиридоновского асфальтитов [37]. Это свидетельствует о том, что, независимо от типа НДС, перечисленные соединения являются неотъемлемой частью структурных фрагментов молекул асфальтенов. Различия в молекулярно-массовом распределении этих соединений отражают специфику строения молекул асфальтенов, связанную с геохимической историей нефтяных систем.

Следует также отметить, что структурные фрагменты, связанные в молекулах асфальтенов алифатическими связями C-S и C-O, которые характеризуются низкой термической стабильностью, будут присутствовать в составе светлых продуктов переработки исследованных нефтей. Этот факт необходимо учитывать при выборе технологических решений получения на их основе высококачественных нефтепродуктов.

\section{Состав «мальтенов»}

Согласно результатам хроматографического разделения, основную массу «мальтенов» в составе асфальтенов как типичной метано-нафтеновой, так и тяжелой нафтено-ароматической нефтей составляют полярные соединения фракций В $(60,6$ и $59,7 \%$ соответственно), среди которых, по данным ИК-спектроскопии, присутствуют кислоты, амиды и сульфоксиды $[22,24]$.

Малополярные соединения фракций А «мальтенов» в обоих случаях представлены нормальными и разветвленными алканами, алкилциклопентанами, алкилциклогексанами, стеранами $\left(\mathrm{C}_{21}-\mathrm{C}_{22}\right.$ прегнанами, $\mathrm{C}_{27}, \mathrm{C}_{28}$ диахолестанами, $\mathrm{C}_{27}, \mathrm{C}_{28}, \mathrm{C}_{29}$ холестанами) и терпанами (хейлантанами от $\mathrm{C}_{23}$ до $\mathrm{C}_{29}$, тетрациклическим терпаном $\mathrm{C}_{24}$, рядом гопанов от $\mathrm{C}_{27}$ до $\mathrm{C}_{32}$ ), н-алкилбензолами, алкилтолуолами, алкилксилолами, нафталинами, фенантренами, бензо- и дибензотиофенами, дибензофурана- ми, карбазолами и бензокарбазолами [22-24].

Особенностью «мальтенов» тяжелой нафтеноароматической нефти является присутствие в их составе более широкого набора трициклических терпанов (хейлантанов) с максимумом на $\mathrm{C}_{23}$ и пониженным относительным содержанием гомологов выше $\mathrm{C}_{26}$ (рис. 3). Такой характер распределения этих УВ-биомаркеров может указывать на микробиологическую переработку исходного органического вещества данной нефти [38].

Существенные отличия наблюдаются и в составе АУ и ГОС «мальтенов» тяжелой нафтено-ароматической нефти. Так, среди моноаренов дополнительно идентифицированы фитанилбензолы, фенилалканы с различным положением фенильного заместителя в алкильной цепи и алкилтриметилбензолы, среди полициклических аренов - тетра- и пентациклические АУ, фенил- и нафтенозамещенные структуры. Среди ГОС «мальтенов» нафтено-ароматической нефти установлено присутствие нафтобензотиофенов, флуоренонов и этиловых эфиров высших жирных кислот. Ранее этиловые эфиры алифатических кислот были определены в составе «мальтенов» асфальтеновых агрегатов нефтей северо-запада Китая [39].

Отличительной особенностью «мальтенов» типичной метано-нафтеновой нефти является присутствие 1- и 2-алкенов с четным числом атомов углерода в цепи в составе УВ и более высокомолекулярных азоторганических соединений - дибензокарбазолов [22].

По литературным данным [40], окклюдированные соединения - это продукты раннего преобразования керогена. Поэтому можно предположить, что присутствие идентифицированных соединений в составе «мальтенов» обусловлено их клатрацией с макромолекулярными образованиями асфальтенов, захватывающими эти соединения в полые ячейки своих структур.

\section{Заключение}

Из обобщения результатов проведенного исследования следует:

- независимо от химической природы нефтей, в составе их асфальтенов присутствуют BMA, HМА и соединения, адсорбируемые и/или окклюдированные молекулами асфальтеновых компонентов, - «мальтены». Основной вклад в состав асфальтеновых компонентов вносят BMA. Тяжелая нафтено-ароматическая нефть отличается повышенным содержанием BMA, типичная метано-нафтеновая нефть - более высоким содержанием НМА и почти в два раза большим содержанием «мальтенов»;

- средние молекулы BMA тяжелой нафтено-ароматической нефти характеризуются более высокими значениями MM, большим количеством атомов углерода в ароматических и нафтеновых фрагментах и большим числом структурных единиц. Особенностью средних молекул BMA типичной метано-нафтеновой нефти 

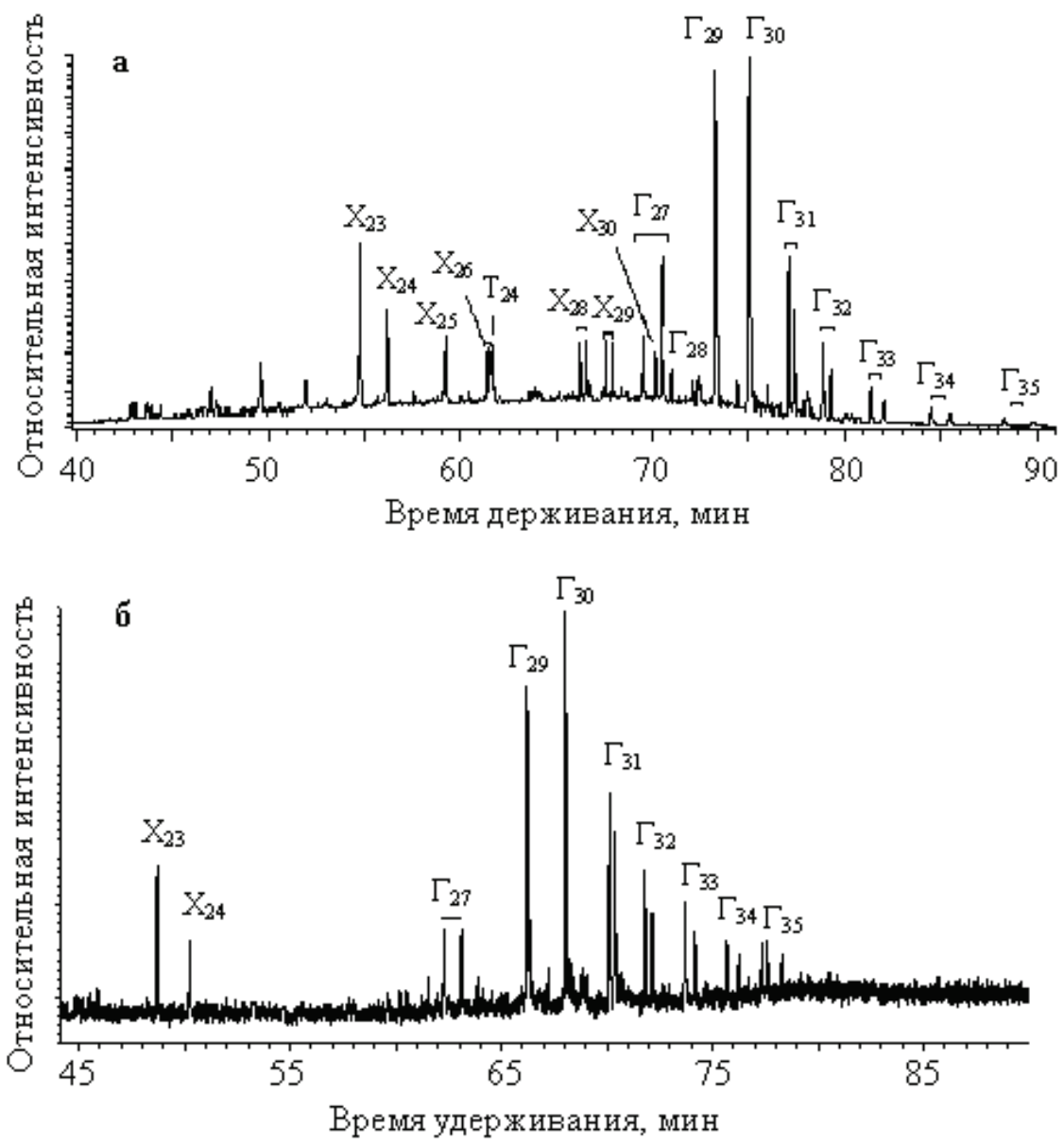

$\mathrm{X}$ - хейлантаны (трицикланы), T - тетрацикланы, Г - гопаны (пентацикланы)

Цифры у буквенных обозначений - количество атомов углерода $\mathrm{X}$ - cheilanthanes (tricyclans), $\mathrm{T}$ - tetracyclanes, $\Gamma$ - hopanes (pentacyclanes) Index numbers are the number of carbon atoms

Рис. 3. Масс-хроматограмма фракции А «мальтенов» нафтено-ароматической (а) и метано-нафтеновой (б) нефтей по иону с $m / z 191$

Fig. 3. Mass-chromatogram for A fraction of «petrolene» in naphthenic-aromatic (a) and methane-naphthenic (6) oils at the ion with $m / z 191$

являются более крупные размеры структурных единиц, обусловленные большим развитием нафтеновых и алифатических фрагментов. Средние молекулы BMА нефтей обоих типов богаты кислородом и серой, часть из которых участвует в образовании эфирных и сульфидных мостиков, связывающих в молекулах асфальтенов отдельные структурные фрагменты между собой или с поликонденсированным ядром;

- среди соединений, связанных в молекулах BMA как әфирными, так и сульфидными мостиками, присутствуют н-алканы, алкилциклопентаны, алкилциклогексаны, стераны, терпаны, н-алкилбензолы и н-алкилтолуолы. Одни и те же представители «серосвязанных» и «эфиросвязанных» нафтенов и ароматических УВ в структуре молекул ВМА обеих нефтей имеют сходное распределение. «Связанные» налканы в случае типичной метано-нафтеновой нефти характеризуются большим числом ато- мов углерода в цепи и сдвигом максимума распределения в высокомолекулярную область. Отличительной особенностью метано-нафтеновой нефти является также наличие в составе «серосвязанных» фрагментов н-алкенов и непредельных стеранов и более широкого спектра полициклических АУ;

- основную массу «мальтенов» в составе асфальтеновых компонентов и метано-нафтеновой и нафтено-ароматической нефтей составляют полярные соединения, в том числе кислоты, амиды и сульфоксиды, имеющие сложное строение. В составе малополярных соединений "мальтенов» установлены те же классы УВ, что и в составе «связанных" фрагментов. Особенностью «мальтенов» тяжелой нафтено-ароматической нефти является присутствие в их составе более широкого набора полициклических структур, в том числе трициклических терпанов, тетра- и пентациклических АУ, а также фенил- и нафтенопро- 
изводных АУ, особенностью «мальтенов» типичной метано-нафтеновой нефти - присутствие в их составе н-алкенов и дибензокарбазолов.

Выявленные различия в составе и структуре изученных асфальтенов, вероятнее всего, связаны с условиями залегания продуктивных нефтяных залежей.

\section{СПИСОК ЛИТЕРАТУРЫ}

1. Distribution Features of Biomarker Hydrocarbons in Asphaltene Thermolysis Products of Different Fractional Compositions (Using as an Example 0ils from Carbonate Deposits of Tatarstan Oilfields) / G.N. Gordadze, M.V. Giruts, V.N. Koshelev, T.N. Yusupova // Petroleum Chemistry. - 2015. - V. 55. - № 1. - P. 22-31.

2. Pan Y.H., Liao Y.H., Sun Y.G. The Characteristics of Bound Biomarkers Released from Asphaltenes in a Sequence of Naturally Biodegraded Oils // Organic Geochemistry. - 2017. - V. 111. P. $56-66$.

3. Nanoaggregates of Diverse Asphaltenes by Mass Spectrometry and Molecular Dynamics / W.G. Wang, C. Taylor, H. Hu, K.L. Humphries, A. Jaini, M. Kitimet, T. Scott, Z. Stewart, K.J. Ulep, S. Houck, A. Luxon, B.Y. Zhang, B. Miller, C.A. Parish, A.E. Pomerantz, O.C. Mullins, R.N. Zare // Energy and Fuels. - 2017. - V. 31. - № 9. - P. 9140-9151.

4. Analysis of Asphaltene Instability Using Diffusive and Thermodynamic Models during Gas Charges into Oil Reservoirs J.Y. Zuo, S. Pan, K. Wang, O.C. Mullins, H. Dumont, L. Chen, V. Mishra, J. Canas // Energy and Fuels. - 2017. - V. 31. № 4. - P. 3717-3728.

5. Tracing the Compositional Changes of Asphaltenes after Hydroconversion and Thermal Cracking Processes by High-Resolution Mass Spectrometry / M.L. Chacon-Patino, C. Blanco-Tirado, J.A. Orrego-Ruiz, A. Gomez-Escudero, M.Y. Combariza // Energy and Fuels. - 2015. - V. 29. - № 10. - P. 6330-6341.

6. Structural Transformations of Asphaltenes during Hydroconversion of Vacuum Residue with Recycling the Hydroconversion Product Distillation Residue / Kh.M. Kadiev, O.V. Zaytseva, E.E. Magomadov, E.A. Chernysheva, N.V. Oknina, A.E. Batov, M.Kh. Kadieva, V.M. Kapustin, S.N. Khadzhiev // Petroleum Chemistry. - 2015. - V. 55. - № 6. - P. 487-496.

7. Unraveling the Molecular Structures of Asphaltenes by Atomic Force Microscopy / B. Schuler, G. Meyer, D. Pena, 0.C. Mullins, L. Gross // Journal of the American Chemical Society - 2015. V. 137. - № 31. - P. 9870-9876.

8. Review on Aggregation of Asphaltene vis-a-vis Spectroscopic Studies / A.K. Ghosh, P. Chaudhuri, B. Kumar, S.S. Panja // Fuel. - 2016. - V. 185. - P. 541-554.

9. Molecular Structure and Association Behavior of Petroleum Asphaltene / Z.T. Chen, L.H. Zhang, S.Q. Zhao, Q. Shi, C.M. Xu // Structure and Bonding. - 2016. - V. 168. - P. 1-38.

10. Laser-Based Mass Spectrometric Assessment of Asphaltene Molecular Weight, Molecular Architecture, and Nanoaggregate Number / A.E. Pomerantz, Q.H. Wu, 0.C. Mullins, R.N. Zare // Energy and Fuels. - 2015. - V. 29. - № 5. - P. 2833-2842.

11. Evdokimov I.N., Fesan A.A., Losev A.P. New Answers to the 0ptical Interrogation of Asphaltenes: Monomers and Primary Aggregates from Steady-State Fluorescence Studies // Energy and Fuels. - 2016. - V. 30. - № 6. - P. 4494-4503.

12. Changes in Asphaltene Structure during Thermal Cracking of Residual Oils: XRD Study / F.S. AlHumaidan, A. Hauser, M.S. Rana, H.M.S. Lababidi, M. Behbehani // Fuel. - 2015. V. 150 . - P. 558-564.

13. Chacon-Patino M.L., Rowland S.M., Rodgers R.P. Advances in Asphaltene Petroleomics. Part 1: Asphaltenes are Composed of
Полученные результаты расширяют наши представления о строении нефтяных асфальтенов, имеют значение для создания новых управляемых способов переработки углеводородного сырья, а также для понимания путей катагенетического преобразования органического вещества осадочных пород.

Abundant Island and Archipelago Structural Motifs // Energy and Fuels. - 2017. - V. 31. - № 12. - P. 13509-13518.

14. Exploring Occluded Compounds and their Interactions with Asphaltene Networks Using High-Resolution Mass Spectrometry / M.L. Chacon-Patino, S.J. Vesga-Martinez, C. Blanco-Tirado, J.A. Orrego-Ruiz, A. Gomez-Escudero, M.Y. Combariza // Energy and Fuels. - 2016. - V. 30. - № 6. - P. 4550-4561.

15. Geochemical Evolution of Occluded Hydrocarbons inside Geomacromolecules: a Review / B. Cheng, J. Zhao, C.P. Yang, Y.K. Tian, Z.W. Liao // Energy and Fuels. - 2017. - V. 31. - № 9. P. $8823-8832$.

16. Toward the Asphaltene Structure by Electron Paramagnetic Resonance Relaxation Studies at High Fields (3.4 T) / G.V. Mamin, M.R. Gafurov, R.V. Yusupov, I.N. Gracheva, Yu.M. Ganeeva, T.N. Yusupova, S.B. Orlinskii // Energy and Fuels. - 2016. V. 30, - № 9. - P. 6942-6946.

17. Influence of Resins and Asphaltenes on the Structural and Rheological Properties of Petroleum Disperse Systems / D.V. Nelyubov, L.P. Semikhina, D.A. Vazhenin, I.A. Merkul'ev // Petroleum Chemistry. - 2017. - V. 57. - № 3. - P. 203-208.

18. Sjoblom J., Simon S., Xu Z.H. Model Molecules Mimicking Asphaltenes // Advances in Colloid and Interface Science. - 2015. V. 218. - P. 1-16.

19. Rogel E., Moir M. Effect of Precipitation Time and Solvent Power on Asphaltene Characteristics // Fuel. - 2017. - V. 208. P. 271-280.

20. Torkaman M., Bahrami M., Dehghani M. Influence of Temperature on Aggregation and Stability of Asphaltenes. I. Perikinetic Aggregation // Energy and Fuels. - 2017. - V. 31. - № 10. P. $11169-11180$.

21. Molina D., Leon E.A., Chaves-Guerrero A. Understanding the Effect of Chemical Structure of Asphaltenes on Wax Crystallization of Crude Oils from Colorado Oil Field // Energy and Fuels. 2017. - V. 31. - № 9. - P. 8997-9005.

22. Химический состав нефти Крапивинского месторождения (сообщение 3) / В.П. Сергун, Т.В. Чешкова, Т.А. Сагаченко, P.С. Мин // Известия Томского политехнического университета. Инжиниринг георесурсов. - 2017. - Т. 328. - № 7. C. $59-66$.

23. Characteristic Structural Features of Asphaltene Macromolecules in Heavy Crude Oil from the Usinsk Field / E.Yu. Kovalenko, V.P. Sergun, R.S. Min, T.A. Sagachenko // Chemistry and technology of fuels and oils. -2014. - V. 49. - № 6. - P. 522-531.

24. Low-Molecular-Mass Asphaltene Compounds from Usa Heavy Oil / V.P. Sergun, E.Yu. Kovalenko, T.A. Sagachenko, R.S. Min // Petroleum Chemistry. - 2014. - V. 54. - № 2. - P. 83-87.

25. Structural Units with Sulfur and Ether/Ester Bonds in Molecules of High- and Low-Molecular-Weight Asphaltenes of Usa Heavy Oil / V.P. Sergun, T.V. Cheshkova, T.A. Sagachenko, R.S. Min // Petroleum Chemistry, - 2016. - V. 56. - № 1. - P. 10-15.

26. Химический состав нефти Крапивинского месторождения (сообщение 1) / А.Э. Торломоева, Т.В. Чешкова, Е.Ю. Коваленко, T.А. Сагаченко // Известия Томского политехнического университета. - 2015. - Т. 326. - № 2. - С. 48-55.

27. Physical-chemical and complex EOR/IOR technologies for the Permian-Carboniferous deposit of heavy oil of the Usinskoye oil field / L.K. Altunina, V.A. Kuvshinov, I.V. Kuvshinov, L.A. Sta- 
syeva, M.V. Chertenkov, L.S. Shkrabyuk, D.V. Andreev // Neftyanoe Khozyaystvo - Oil Industry. - 2017. - № 7. - P. 26-29.

28. Molecular Structure of Athabasca Asphaltene: Sulfide, Ether, and Ester Linkages / P. Peng, A. Morales-Izquierdo, A. Hogg, 0.P. Strauaz // Energy and Fuels. - 1997. - V. 11. - № 5. P. 1171-1187.

29. Golovko A.K., Kam'yanov V.F., Ogorodnikov V.D. High-Molecular Heteroatomic Components of Crude Oils of the Timan-Pechora Petroliferous Basin // Russian Geology and Geophysics. 2012. - V. 53. - № 12 - P. 1374-1381.

30. Smirnov M.B., Poludetkina E.N., Vanyukova N.A. Unsaturated Hydrocarbons of Thermocatalytic Origin in Some Oils and Bitumens from the Southern Part of Anadyr Basin // Petroleum Chemistry. - 2010. - V. 50. - № 3. - P. 189-199.

31. Composition and Structure of Resinous Components of Heavy Oil from the Usa Oilfield / T.V. Cheshkova, E.Yu. Kovalenko, N.N. Gerasimova, T.A. Sagachenko, R.S. Min // Petroleum Chemistry. - 2017. - V. 57. - № 1. - P. 31-38.

32. Chemical Nature of the Oil and Tarry-Asphaltene Components of Natural Bitumen from the Ashal'chinsk Deposit in Tatarstan / T.A. Sagachenko, V.P. Sergun, T.V. Cheshkova, E.Y. Kovalenko, R.S. Min // Solid Fuel Chemistry. - 2015. - V. 49. - № 6. P. $349-355$.

33. Антипенко В.Р., Чешкова Т.В. Состав соединений, связанных через эфирные и сульфидные мостики в маслах природного битума Ашальчинского месторождения // Известия Томского политехнического университета. - 2014. - Т. 324. - № 3. C. $16-21$.
34. Payzant J.D., Lown E.M., Strausz 0.P. Structural Units of Athabasca Asphaltene - the Aromatics with a Linear Carbon Framework // Energy and Fuels. - 1991. - V. 5. - № 3. - P. 445-453.

35. The Organic Geochemistry of Asphaltenes and Occluded Biomarkers / L.R. Snowdon, J.K. Volkman, Z.R. Zhang, G.L. Tao, P. Liu // Organic Geochemistry. - 2016. - V. 91. - P. 3-15.

36. Антипенко В.Р. Термические превращения высокосернистого природного асфальтита: геохимические и технологические аспекты. - Новосибирск: Наука РАН, 2013. - 184 с.

37. Characteristic Features of the Hydrocarbon Composition of Spiridonovskoe (Tatarstan) and Pitch Lake (Trinidad and Tobago) Asphaltites / G.P. Kayukova, B.V. Uspensky, I.M. Abdrafikova, R.Z. Musin // Petroleum Chemistry. - 2016. - V. 56. - № 7. P. $572-579$.

38. Гордадзе Г.Н. Углеводороды в нефтяной геохимии. Теория и практика. - М.: Российский государственный университет нефти и газа имени И.М. Губкина, 2015. - 559 с.

39. Thermal Evolution of Adsorbed/Occluded Hydrocarbons inside Kerogens and its Significance as Exemplified by One Low-Matured Kerogen from Santanghu Basin, Northwest China / B. Cheng, J. Du, Y. Tian, H. Liu, Z. Liao // Energy and Fuels. - 2016. V. 30. - № 6. - P. 4529-4536.

40. Some Biogenic-Related Compounds Occluded inside Asphaltene Aggregates / C. Yang, Z. Liao, L. Zhang, P. Creux // Energy and Fuels. - 2009. - V. 23. - № 1-2. - P. 820-827.

Поступила 28.03.2018 г.

\section{Информация об авторах}

Чешкова T.B., кандидат химических наук, младший научный сотрудник лаборатории гетероорганических соединений нефти Института химии нефти Сибирского отделения Российской академии наук.

Сергун В.П., кандидат химических наук, научный сотрудник лаборатории гетероорганических соединений нефти Института химии нефти Сибирского отделения Российской академии наук.

Коваленко E.Ю., кандидат химических наук, старший научный сотрудник лаборатории гетероорганических соединений нефти Института химии нефти Сибирского отделения Российской академии наук.

Сагаченко T.A., доктор химических наук, ведущий научный сотрудник лаборатории гетероорганических соединений нефти Института химии нефти Сибирского отделения Российской академии наук.

Мин P.C., доктор химических наук, главный научный сотрудник лаборатории гетероорганических соединений нефти Института химии нефти Сибирского отделения Российской академии наук. 


\title{
STRUCTURE OF ASPHALTENES OCCURRING IN OILS OF DIFFERENT CHEMICAL NATURE
}

\author{
Tatyana V. Cheshkova', \\ chtv12@mail.ru
}

\author{
Valeriy P. Sergun', \\ sergyn@ipc.tsc.ru
}

\section{Elena Yu. Kovalenko', azot@ipc.tsc.ru}

\author{
Tatyana A. Sagachenko', \\ dissovet@ipc.tsc.ru \\ Raisa S. Min', \\ Igosn@ipc.tsc.ru \\ 1 Institute of petroleum chemistry Siberian branch Russian academy of science, \\ 4, Akademichesky Avenue, Tomsk, 634055, Russia.
}

The relevance of the work is caused by the need to obtain and generalize information on composition and structure of asphaltene components in oils of different chemical nature, since the features of structural characteristics of asphaltenes have a significant effect on the depth of their thermal destruction. Recently the works in this area are of particular importance due to the steady increase of heavy oils, which differ from traditional oils with high contents of asphaltenes, in compositions of explored and recoverable reserves.

The aim of the research is the comparative analysis of structural-group compositions of asphaltenes in typical methane-naphthenic oil and heavy oil of a naphthenic-aromatic base, the molecular composition of structural fragments bonded in molecules of their asphaltene components through sulfide and ether bridges, and covalently unbonded compounds.

Research methods: elemental analysis, cryoscopy in benzene, extraction, liquid-adsorption chromatography, selective chemical destruction of sulfide and ether bonds, ${ }^{\prime} H$ NMR spectroscopy, structural-group analysis, chromatography-mass spectrometry.

Results. The authors have carried out the comparative analysis of composition and structure of asphaltene components in methanenaphthenic and naphthenic-aromatic oils and identified the similarities and differences in their structural-group compositions, compositions of fragments bonded in asphaltene molecules via ether and sulfide bridges and in the compositions of compounds occluded by macromolecules of asphaltene substances. Using the methods of mild chemical destruction of sulfide and ether bonds, $n$-alkanes, cyclohexanes, steranes, hopanes, $n$-alkylbenzenes and $n$-alkyltoluenes were considered the most common fragments of asphaltene macromolecules in methane-naphthenic and naphthenic-aromatic types of oils. A peculiarity of asphaltene molecules in methane-naphthenic oil is the presence of alkenes and unsaturated steranes in composition of their structural fragments, while that in naphthenic-aromatic oil - pregnanes, cheilanthanes, thiophenic compounds and ethyl esters of alkane acids.

\section{Key words:}

Oil, asphaltenes, structural-group composition, selective chemical degradation, sulfur-and ether-bonded fragments, composition, saturated and aromatic hydrocarbons, heteroorganic compounds.

\section{REFERENCES}

1. Gordadze G.N., Giruts M.V., Koshelev V.N., Yusupova T.N. Distribution Features of Biomarker Hydrocarbons in Asphaltene Thermolysis Products of Different Fractional Compositions (Using as an Example Oils from Carbonate Deposits of Tatarstan Oilfields). Petroleum Chemistry, 2015, vol. 55, no. 1, pp. 22-31.

2. Pan Y.H., Liao Y.H., Sun Y.G. The Characteristics of Bound Biomarkers Released from Asphaltenes in a Sequence of Naturally Biodegraded Oils. Organic Geochemistry, 2017, vol. 111, pp. 56-66.

3. Wang W.G., Taylor C., Hu H., Humphries K.L., Jaini A., Kitimet M., Scott T., Stewart Z., Ulep K.J., Houck S., Luxon A., Zhang B.Y., Miller B., Parish C.A., Pomerantz A.E., Mullins 0.C., Zare R.N. Nanoaggregates of Diverse Asphaltenes by Mass Spectrometry and Molecular Dynamics. Energy and Fuels, 2017, vol. 31, no. 9, pp. 9140-9151.

4. Zuo J.Y., Pan S., Wang K., Mullins 0.C., Dumont H., Chen L., Mishra V., Canas J. Analysis of Asphaltene Instability Using Diffusive and Thermodynamic Models during Gas Charges into Oil Reservoirs. Energy and Fuels, 2017, vol. 31, no. 4, pp. $3717-3728$.
5. Chacon-Patino M.L., Blanco-Tirado C., Orrego-Ruiz J.A., Gomez-Escudero A., Combariza M.Y. Tracing the Compositional Changes of Asphaltenes after Hydroconversion and Thermal Cracking Processes by High-Resolution Mass Spectrometry. Energy and Fuels, 2015, vol. 29, no. 10, pp. 6330-6341.

6. Kadiev Kh.M., Zaytseva O.V., Magomadov E.E., Chernysheva E.A., Oknina N.V., Batov A.E., Kadieva M.Kh., Kapustin V.M., Khadzhiev S.N. Structural Transformations of Asphaltenes during Hydroconversion of Vacuum Residue with Recycling the Hydroconversion Product Distillation Residue. Petroleum Chemistry, 2015, vol. 55, no. 6, pp. 487-496.

7. Schuler B., Meyer G., Pena D., Mullins 0.C., Gross L. Unraveling the Molecular Structures of Asphaltenes by Atomic Force Microscopy. Journal of the American Chemical Society, 2015, vol. 137, no. 31 , pp. $9870-9876$.

8. Ghosh A.K., Chaudhuri P., Kumar B., Panja S.S. Review on Aggregation of Asphaltene vis-a-vis Spectroscopic Studies. Fuel, 2016, vol. 185, pp. 541-554.

9. Chen Z.T., Zhang L.H., Zhao S.Q., Shi Q., Xu C.M. Molecular Structure and Association Behavior of Petroleum Asphaltene. Structue and Bonding, 2016, vol. 168, pp. 1-38. 
10. Pomerantz A.E., Wu Q.H., Mullins 0.C., Zare R.N. Laser-Based Mass Spectrometric Assessment of Asphaltene Molecular Weight, Molecular Architecture, and Nanoaggregate Number. Energy and Fuels, 2015, vol. 29, no. 5, pp. 2833-2842.

11. Evdokimov I.N., Fesan A.A., Losev A.P. New answers to the optical interrogation of asphaltenes: monomers and primary aggregates from steady-state fluorescence studies. Energy and Fuels, 2016, vol. 30, no. 6, pp. 4494-4503.

12. AlHumaidan F.S., Hauser A., Rana M.S., Lababidi H.M.S., Behbehani M. Changes in Asphaltene Structure during Thermal Cracking of Residual Oils: XRD Study. Fuel, 2015, vol. 150, pp. 558-564.

13. Chacon-Patino M.L., Rowland S.M., Rodgers R.P. Advances in Asphaltene Petroleomics. Part 1: Asphaltenes Are Composed of Abundant Island and Archipelago Structural Motifs. Energy and Fuels, 2017, vol. 31, no. 12, pp. 13509-13518.

14. Chacon-Patino M.L., Vesga-Martinez S.J., Blanco-Tirado C., Orrego-Ruiz J.A., Gomez-Escudero A., Combariza M.Y. Exploring Occluded Compounds and Their Interactions with Asphaltene Networks Using High-Resolution Mass Spectrometry. Energy and Fuels, 2016, vol. 30, no. 6, pp. 4550-4561.

15. Cheng B., Zhao J., Yang C.P., Tian Y.K., Liao Z.W. Geochemical Evolution of Occluded Hydrocarbons inside Geomacromolecules: a Review. Energy and Fuel, 2017, vol. 31, no. 9, pp. 8823-8832.

16. Mamin G.V., Gafurov M.R., Yusupov R.V., Gracheva I.N., Ganeeva Yu.M., Yusupova T.N., Orlinskii S.B. Toward the Asphaltene Structure by Electron Paramagnetic Resonance Relaxation Studies at High Fields (3.4 T). Energy and Fuels, 2016, vol. 30, no. 9 , pp. 6942-6946.

17. Nelyubov D.V., Semikhina L.P., Vazhenin D.A., Merkul'ev I.A. Influence of Resins and Asphaltenes on the Structural and Rheological Properties of Petroleum Disperse Systems. Petroleum Chemistry, 2017, vol. 57, no. 3, pp. 203-208.

18. Sjoblom J., Simon S., Xu Z.H. Model Molecules Mimicking Asphaltenes. Advances in Colloid and Interface Science, 2015, vol. 218, pp. 1-16.

19. Rogel E., Moir M. Effect of Precipitation Time and Solvent Power on Asphaltene Characteristics. Fuel, 2017, vol. 208, pp. 271-280.

20. Torkaman M., Bahrami M., Dehghani M. Influence of Temperature on Aggregation and Stability of Asphaltenes. I. Perikinetic Aggregation. Energy and Fuels, 2017, vol. 31, no. 10, pp. $11169-11180$.

21. Molina D., Leon E.A., Chaves-Guerrero A. Understanding the Effect of Chemical Structure of Asphaltenes on Wax Crystallization of Crude Oils from Colorado Oil Field. Energy and Fuels, 2017, vol. 31, no. 9, pp. 8997-9005.

22. Sergun V.P., Cheshkova T.V., Sagachenko T.A., Min R.S. Chemical composition of petroleum from Krapivinskoye oilfield (message 3). Bulletin of the Tomsk Polytechnic University. Geo Assets Engineering, 2017, vol. 328, no. 7, pp. 59-66. In Rus.

23. Kovalenko E.Yu., Sergun V.P., Min R.S., Sagachenko T.A. Characteristic Structural Features of Asphaltene Macromolecules in Heavy Crude Oil from the Usinsk Field. Chemistry and technology of fuels and oils, 2014, vol. 49, no. 6, pp. 522-531.

24. Sergun V.P., Kovalenko E.Yu., Sagachenko T.A., Min R.S. LowMolecular-Mass Asphaltene Compounds from Usa Heavy Oil. Petroleum Chemistry, 2014, vol. 54, no. 2, pp. 83-87.

25. Sergun V.P., Cheshkova T.V., Sagachenko T.A., Min R.S. Structural units with Sulfur and Ether/Ester Bonds in Molecules of High- and Low-Molecular-Weight Asphaltenes of Usa Heavy Oil. Petroleum Chemistry, 2016, vol. 56, no. 1, pp. 10-15.
26. Torlomoeva A.E., Cheshkova T.V., Kovalenko E.Yu., Sagachenko T.A. Chemical composition of petroleum from Krapivinskoye oilfield (message 1). Bulletin of the Tomsk Polytechnic University, 2015, vol. 326, no. 2, pp. 48-55. In Rus.

27. Altunina L.K., Kuvshinov V.A., Kuvshinov I.V., Stasyeva L.A., Chertenkov M.V., Shkrabyuk L.S., Andreev D.V. Physical-chemical and complex EOR/IOR technologies for the Permian-Carboniferous deposit of heavy oil of the Usinskoye oil field. Neftyanoe Khozyaystvo - Oil Industry, 2017, no. 7, pp. 26-29.

28. Peng P., Morales-Izquierdo A., Hogg A., Strauaz 0.P. Molecular Structure of Athabasca Asphaltene: Sulfide, Ether, and Ester Linkages. Energy and Fuels, 1997, vol. 11, no. 5, pp. 1171-1187.

29. Golovko A.K., Kam'yanov V.F., Ogorodnikov V.D. High-Molecular Heteroatomic Components of Crude Oils of the Timan-Pechora Petroliferous Basin. Russian Geology and Geophysics, 2012, vol. 53, no. 12, pp. 1374-1381.

30. Smirnov M.B., Poludetkina E.N., Vanyukova N.A. Unsaturated Hydrocarbons of Thermocatalytic Origin in Some Oils and Bitumens from the Southern Part of Anadyr Basin. Petroleum Chemistry, 2010, vol. 50, no 3, pp. 189-199.

31. Cheshkova T.V., Kovalenko E.Yu., Gerasimova N.N., Sagachenko T.A., Min R.S. Composition and Structure of Resinous Components of Heavy Oil from the Usa Oilfield. Petroleum Chemistry, 2017, vol. 57, no. 1, pp. 31-38.

32. Sagachenko T.A., Sergun V.P., Cheshkova T.V., Kovalenko E.Y., Min R.S. Chemical Nature of the Oil and Tarry-Asphaltene Components of Natural Bitumen from the Ashal'chinsk Deposit in Tatarstan. Solid Fuel Chemistry, 2015, vol. 49, no. 6, pp. 349-355.

33. Antipenko V.R., Cheshkova T.V. Composition of compounds bonded through ether and sulfide bridges in oils of natural bitumen from the Ashalchinsk deposit. Bulletin of the Tomsk Polytechnic University, 2014, vol. 324, no. 3, pp. 16-21. In Rus.

34. Payzant J.D., Lown E.M., Strausz O.P. Structural units of Athabasca Asphaltene - the Aromatics with a Linear Carbon Framework. Energy and Fuels, 1991, vol. 5, no. 3, pp. 445-453.

35. Snowdon L.R., Volkman J.K., Zhang Z.R., Tao G.L., Liu P. The Organic Geochemistry of Asphaltenes and Occluded Biomarkers, Organic Geochemistry, 2016, vol. 91, no. 1, pp. 3-15.

36. Antipenko V.R. Termicheskie prevrashcheniya vysokosernistogo prirodnogo asfaltita: geokhimicheskie i tekhnologicheskie aspekty [Thermal transformations of high-sulfur natural asphaltite: geochemical and technological aspects]. Novosibirsk, Nauka Publ., $2013.184 \mathrm{p}$.

37. Kayukova G.P., Uspensky B.V., Abdrafikova I.M., Musin R.Z. Characteristic Features of the Hydrocarbon Composition of Spiridonovskoe (Tatarstan) and Pitch Lake (Trinidad and Tobago) Asphaltites. Petroleum Chemistry, 2016, vol. 56, no. 7, pp. 572-579.

38. Gordadze G.N. Uglevodorody v neftyanoy geokhimii. Teoriya $i$ praktika [Hydrocarbons in petroleum geochemistry. Theory and practice]. Moscow, Russian State University of Oil and Gas named after I.M. Gubkina Publ., 2015. 559 p.

39. Cheng B., Du J., Tian Y., Liu H., Liao Z. Thermal Evolution of Adsorbed/Occluded Hydrocarbons inside Kerogens and its Significance as Exemplified by One Low-Matured Kerogen from Santanghu Basin, Northwest China. Energy and Fuels, 2016, vol. 30, no. 6, pp. 4529-4536.

40. Yang C., Liao Z., Zhang L., Creux P. Some Biogenic-Related Compounds Occluded inside Asphaltene Aggregates. Energy and $\mathrm{Fu}$ els, 2009, vol. 23, no. 1-2, pp. 820-827. 


\section{Information about the authors}

Tatyana $V$. Cheshkova, Cand. Sc., junior researcher, Institute of petroleum chemistry Siberian branch Russian academy of science.

Valeriy P. Sergun, Cand. Sc., researcher, Institute of petroleum chemistry Siberian branch Russian academy of science.

Elena Yu. Kovalenko, Cand. Sc., senior researcher, Institute of petroleum chemistry Siberian branch Russian academy of science.

Tatyana A. Sagachenko, Dr. Sc., leading researcher, Institute of petroleum chemistry Siberian branch Russian academy of science.

Raisa S. Min, Dr. Sc, chief researcher, Institute of petroleum chemistry Siberian branch Russian academy of science. 